\title{
Application of Landsat images for quantifying the energy balance under conditions of land use changes in the semi-arid region of Brazil
}

\author{
Antônio H. de C. Teixeira ${ }^{* 1 a}$, Fernando B. T. Hernandez ${ }^{b}$, Hélio L. Lopes ${ }^{\mathrm{c}}$ \\ ${ }^{a}$ Embrapa Semiárido, Petrolina, Brazil; ${ }^{\text {b}}$ Universidade Estadual de São Paulo, Ilha Solteira, São \\ Paulo, Brazil; ${ }^{c}$ Universidade Federal de Pernambuco, Recife, Brazil
}

\begin{abstract}
In the Nilo Coelho irrigation scheme, Brazil, the natural vegetation has been replaced by irrigated agriculture, bringing importance for the quantification of the effects on the energy exchanges between the mixed vegetated surfaces and the lower atmosphere. Landsat satellite images and agro-meteorological stations from 1992 to 2011 were used together, for modelling these exchanges. Surface albedo $\left(\alpha_{0}\right)$, NDVI and surface temperature $\left(T_{0}\right)$ were the basic remote sensing retrieving parameters necessary to calculate the latent heat flux $(\lambda \mathrm{E})$ and the surface resistance to evapotranspiration $\left(\mathrm{r}_{\mathrm{s}}\right)$ on a large scale. The daily net radiation $\left(\mathrm{R}_{\mathrm{n}}\right)$ was obtained from $\alpha_{0}$, air temperature $\left(\mathrm{T}_{\mathrm{a}}\right)$ and short-wave transmissivity $\left(\tau_{\text {sw }}\right)$ throughout the slob equation, allowing the quantification of the daily sensible heat flux $(\mathrm{H})$ by residual in the energy balance equation. With a threshold value for $r_{s}$, it was possible to separate the energy fluxes from crops and natural vegetation. The averaged fractions of $\mathrm{R}_{\mathrm{n}}$ partitioned as $\mathrm{H}$ and $\lambda \mathrm{E}$, were in average 39 and $67 \%$, respectively. It was observed an increase of the energy used for the evapotranspiration process inside irrigated areas from 51\% in 1992 to $80 \%$ in 2011 , with the ratio $\lambda E / R_{n}$ presenting an increase of $3 \%$ per year. The tools and models applied in the current research, can subsidize the monitoring of the coupled climate and land use changes effects in irrigation perimeters, being valuable when aiming the sustainability of the irrigated agriculture in the future, avoiding conflicts among different water users.
\end{abstract}

Keywords: surface albedo, surface temperature, NDVI, latent heat flux, sensible heat flux, surface resistance

\section{INTRODUCTION}

On a large scale, the natural vegetation of the Brazilian semi-arid region, the "Caatinga", has been quickly replaced by irrigated crops in irrigation perimeters, with the most important one being the Nilo Coelho, located in the left bank of the São Francisco river basin. Its construction was completed in 1990 and since then irrigated agriculture has increased, mainly with fruit crops. Water is pumped from the river and applied by micro-sprinklers, hand move sprinklers, drip and centre-pivot systems. The rainy period is concentrated from January to April, with the peak occurring in March. The lowest irrigated area occurs in February, while the highest one is in July ${ }^{1}$.

Considering the situation of land use and climate changes, it is becoming important the development and application of tools for the radiation and energy balance components quantification. Experimentally, the acquirements of these components in the Brazilian semi-arid region have been done in fruit crops and natural vegetation by using the Bowen ratio (BR) method and eddy covariance techniques ${ }^{2}$. However, the difficulties to measure the energy fluxes from mixed ecosystems by field experiments make the use of remote sensing by satellite images a valuable application, what has been done in distinct climate regions ${ }^{3-5}$.

The energy balance methods using satellite measurements have the advantage that, while taking into account the crop growing conditions, they do not require a crop classification. However, for some of them it is necessary the identification of extreme conditions ${ }^{5-7}$ which may be difficult during the rainy seasons. Two algorithms were developed and validated in the Brazilian semiarid region ${ }^{8}$, to obtain the regional values of the evapotranspiration (ET) and the resistance to the

heribert@cpatsa.embrapa.br; phone 005587 3866-3783; Fax: 005587 3866-3815; cpatsa.embrapa.br

Remote Sensing for Agriculture, Ecosystems, and Hydrology XIV, edited by Christopher M. U. Neale, Antonino Maltese, Proc. of SPIE Vol. 8531, 85310P - (c) 2012 SPIE · CCC code: 0277-786/12/\$18 · doi: 10.1117/12.965882 
water fluxes from the surface $\left(r_{s}\right)$, which together with the net radiation $\left(R_{n}\right)$ acquired by the slob equation ${ }^{2,9,10}$ allow the quantification of the latent heat flux $(\lambda \mathrm{E})$ and the sensible heat flux $(\mathrm{H})$. The model for ET estimations, now called SAFER (Simple Algorithm For Evapotranspiration Retrieving), has the advantage of simplicity of application, the absence of the need of neither crop classification nor extreme conditions and the possibility of using daily weather data from either conventional or automatic agrometeorological stations. The use of data from conventional stations is valuable because a historical evaluation of the radiation and energy balance components can be done on a large scale.

The objective of the current research was to combine remote sensing measurements and agrometeorological data for modelling the radiation and energy balance components in the Nilo Coelho irrigation scheme, located in the semiarid region of Brazil, aiming to subsidize the monitoring of the effects on water use by agriculture, under the conditions of fast replacement of the natural vegetation by irrigated crops together with climate change.

\section{MATERIAL AND METHODS}

One conventional and five automatic agrometeorological stations were used together with 10 Landsat images for periods outside the rainy season from 1992 to 2011. Figure 1 shows the locations of the Nilo Coelho scheme and the stations. The conventional one was used to estimate the interpolated values of the daily weather parameters before 2003 by applying simple regression equations, because the absence of automatic stations. Then for all period it was possible the use of grids of incident solar radiation (RS $\downarrow$ ), air temperature $\left(T_{a}\right)$ and reference evapotranspiration $\left(E_{0}\right)$, together with remote sensing retrieving parameters during the steps of acquirements of the radiation and energy balance components on a large scale.

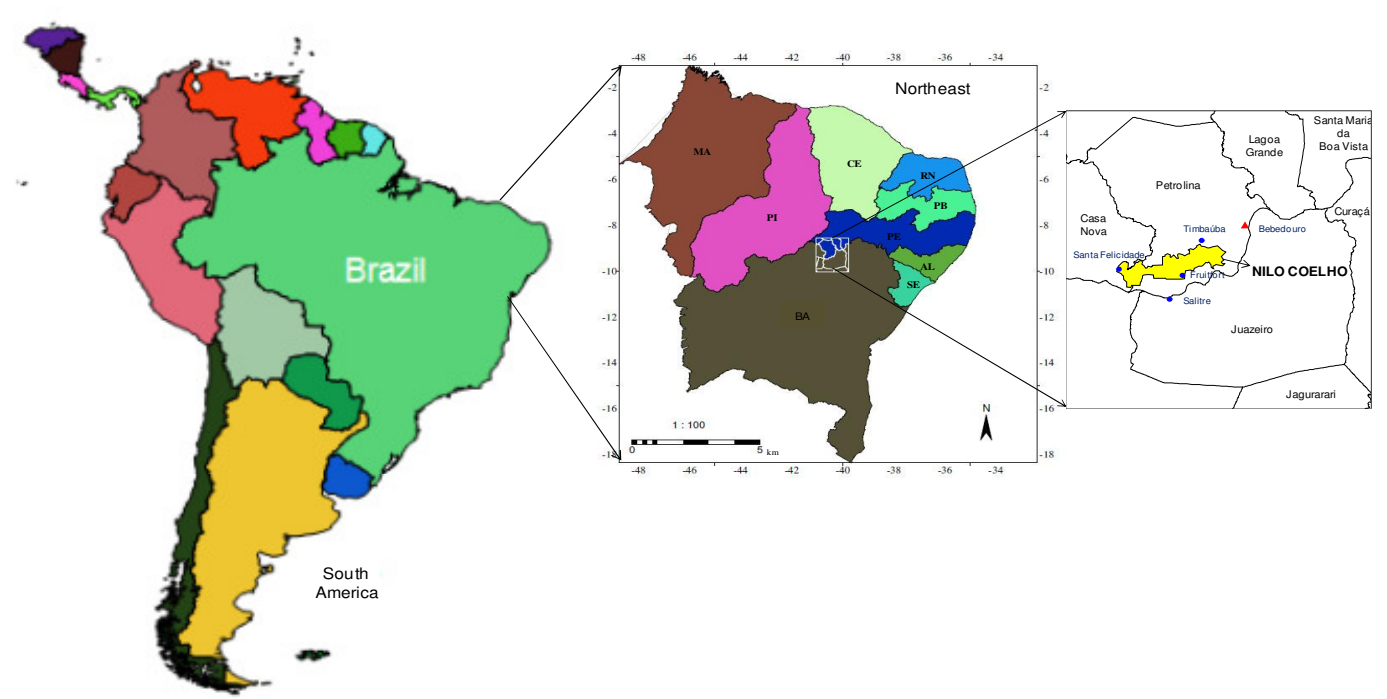

Figure 1. Location of the Nilo Coelho Irrigation scheme and the agrometeorological stations. The round points in the right side represent the automatic stations while the triangle is the place with both, a conventional and an automatic station.

The remote sensing retrieving parameters involved the surface albedo $\left(\alpha_{0}\right)$, surface temperature $\left(T_{0}\right)$ after simple atmospheric corrections and NDVI, which were used to acquire ET and $r_{s}^{8}$ throughout Equations 1 and 2.

$$
\begin{aligned}
& \frac{E T}{\mathrm{ET}_{0}}=\exp \left[\mathrm{a}+\mathrm{b}\left(\frac{\mathrm{T}_{0}}{\alpha_{0} \mathrm{NDVI}}\right)\right] \\
& \mathrm{r}_{\mathrm{s}}=\exp \left[\mathrm{a}\left(\frac{\mathrm{T}_{0}}{\alpha_{0}}\right)(1-\mathrm{NDVI})+\mathrm{b}\right]
\end{aligned}
$$


where $\mathrm{a}$ and $\mathrm{b}$ are regressions coefficients. The model represented by Equation 1 is now named SAFER (Simple Algorithm For Evapotranspiration Retrieving) ${ }^{8}$.

For the daily radiation balance, the large scale incident solar radiation was obtained from the piranometers measurements. The outgoing long (RL $\uparrow$ ) wave radiation was acquired applying the Stefan Boltsman equation with $\mathrm{T}_{0}$ data, while the longwave radiation reaching the surface ( $R L \downarrow$ ) was calculated by using the same equation but with interpolated data of air temperature $\left(T_{a}\right)^{8}$. The daily values of the net radiation $\left(R_{n}\right)$ can be described by the 24-hour values of net shortwave radiation, with a correction term for net longwave radiation for the same time scale ${ }^{2,8-11}$ :

$\mathrm{R}_{\mathrm{n}}=\left(1-\alpha_{0}\right) \mathrm{RS} \downarrow-\mathrm{a} \tau_{\mathrm{sw}}$

where a is the regression coefficient of the relationship between net long wave radiation and atmospheric short-wave transmissivity $\left(\tau_{\mathrm{sw}}\right)$ on a daily scale ${ }^{2,8-11}$.

Because of the $T_{a}$ dependency on longwave radiation via the Stephan Boltzmann equation, previous study investigated further whether the variations of the a coefficient of the Equation 3 could be explained by variations in 24 hours $T_{a}$ values ${ }^{2}$ :

$\mathrm{a}=\mathrm{bT}_{\mathrm{a}}-\mathrm{c}$

where $\mathrm{b}$ and $\mathrm{c}$ are regression coefficients found to be 6.99 and 39.93 , respectively for the Brazilian semi-arid conditions ${ }^{2}$. Interpolated $\mathrm{T}_{\mathrm{a}}$ data from the agrometeorological stations from Figure 1 were then using with Equation 4.

Transforming ET into energy units, $\lambda \mathrm{E}$ was quantified, and $\mathrm{H}$ was obtained as a residual in the energy balance equation, assuming the soil heat flux $(\mathrm{G})$ being zero at the daily time scale:

$\mathrm{H}=\mathrm{R}_{\mathrm{n}}-\lambda \mathrm{E}$

\section{RESULTS AND DISCUSSION}

The daily values of the radiation balance components for ten days outside the rainy period in the Nilo Coelho irrigation scheme, from 1992 to 2011, are presented in Table 1.

Table 1. Daily averages for the radiation balance components in the Nilo Coelho irrigation scheme outside the rainy periods from 1992 to 2011 for each DOY/Year: incident shortwave solar radiation (RS $\downarrow$ ), reflected shortwave solar radiation (RS $\uparrow$ ), downward

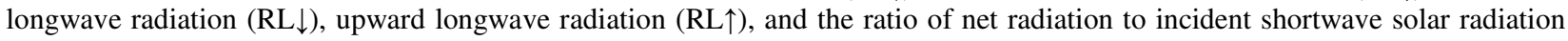
$\left(\mathrm{R}_{\mathrm{n}} / \mathrm{RS} \downarrow\right)$.

\begin{tabular}{|c|c|c|c|c|c|}
\hline DOY/Year & $\begin{array}{c}\mathbf{R S} \downarrow \\
\left(\mathrm{MJ} \mathrm{m}^{-2} \mathbf{d}^{-1}\right) \\
\end{array}$ & $\begin{array}{c}\mathbf{R S} \uparrow \\
\left(\mathbf{M J ~ m}^{-2} \mathbf{d}^{-1}\right) \\
\end{array}$ & $\begin{array}{c}\mathrm{RL} \downarrow \\
\left(\mathrm{MJ} \mathrm{m}^{-2} \mathbf{d}^{-1}\right)\end{array}$ & $\begin{array}{c}\mathrm{RL} \uparrow \\
\left(\mathrm{MJ} \mathrm{m}^{-2} \mathbf{d}^{-1}\right) \\
\end{array}$ & $\begin{array}{c}\mathbf{R}_{\mathbf{n}} / \mathbf{R S} \downarrow \\
(-)\end{array}$ \\
\hline $237 / 1992$ & 23.6 & 4.1 & 31.5 & 34.0 & 0.47 \\
\hline 229/1995 & 20.1 & 3.3 & 33.1 & 39.9 & 0.50 \\
\hline 266/1997 & 22.2 & 3.8 & 36.0 & 45.0 & 0.42 \\
\hline 256/1999 & 21.7 & 3.8 & 33.7 & 40.9 & 0.49 \\
\hline $253 / 2001$ & 21.7 & 4.2 & 34.2 & 41.9 & 0.46 \\
\hline $219 / 2003$ & 23.0 & 4.8 & 31.9 & 40.4 & 0.45 \\
\hline $288 / 2005$ & 25.4 & 4.9 & 34.0 & 43.0 & 0.45 \\
\hline $262 / 2007$ & 23.5 & 4.4 & 33.5 & 41.4 & 0.47 \\
\hline $267 / 2009$ & 24.3 & 4.5 & 34.1 & 42.9 & 0.45 \\
\hline $241 / 2011$ & 22.8 & 4.1 & 32.9 & 40.8 & 0.47 \\
\hline
\end{tabular}

*DOY: Day of the year

The fraction of RS $\downarrow$ transformed in $\mathrm{R}_{\mathrm{n}}$ ranged from $42 \%$ to $50 \%$, averaging $46 \%$, confirming the assumption of this ratio being around $50 \% \%^{2}$, what gives confidence for modelling the large scale daily radiation balance components by using 
Landsat satellite images and agrometeorological stations. The lower value of the ratio $R_{n} / R S \downarrow$ was due to the highest thermal conditions in 1997 (DOY 266), increasing $R L \uparrow\left(45.0 \mathrm{MJ} \mathrm{m}^{-2} \mathrm{~d}^{-1}\right.$ ), and thus lowering $\mathrm{R}_{\mathrm{n}}$. The trend of $\mathrm{R}_{\mathrm{n}} / \mathrm{RS} \downarrow$ along the years is not evident, as it depends on the weather.

An important satellite parameter for the radiation and energy balance modelling is the Normalized Difference Vegetation Index (NDVI), because it is a measured of the leaf areas of different vegetation species, and thus has been used in many modelling processes, including biomass production and water fluxes ${ }^{11}$. Figure 2 presents the spatial variations of the NDVI pixel values in the mixed agro-ecosystems for naturally dry periods from 1992 to 2011 at the Landsat satellite overpass time in the Nilo Coelho irrigation scheme outside the rainy seasons.

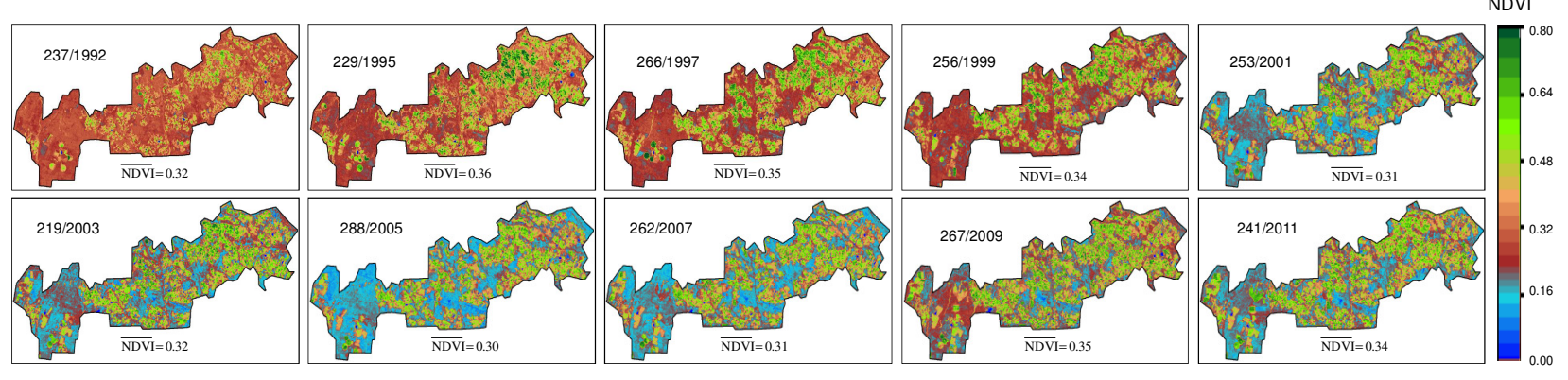

Figure 2. Spatial distributions of the NDVI pixel values for the mixed agro-ecosystems at the Landsat satellite overpass time in the Nilo Coelho irrigation scheme, Brazil, during the driest periods of the year from 1992 to 2001 for each DOY/Year. The bars mean average pixel values and DOY represents Day of the Year.

The variations of the NDVI pixel values along the years is evident in the measure that irrigated areas were increasing, mainly when observing the images for 1992 and 2011, which are for the same period of the year. Considering the mixed agro-ecosystems and all period, the average pixel value for the perimeter is 0.33 , although irrigated areas present values as high as 0.80 . The heterogeneity increased along the years with the standard deviation (SD) from 0.08 in 1992 to 0.17 in 2011, as a consequence of the replacement of "Caatinga" by different irrigated crops. The difficulty to quantify the land use change along the years by using only NDVI values is due to the variability of this indicator with soil moisture. Figure 3 shows the trend of its averaged pixel values together with the accumulated precipitation for each specific Landsat image date. Precipitation data were taken from the conventional station Bebedouro, represented in the right side of the Figure 1 as a triangle.

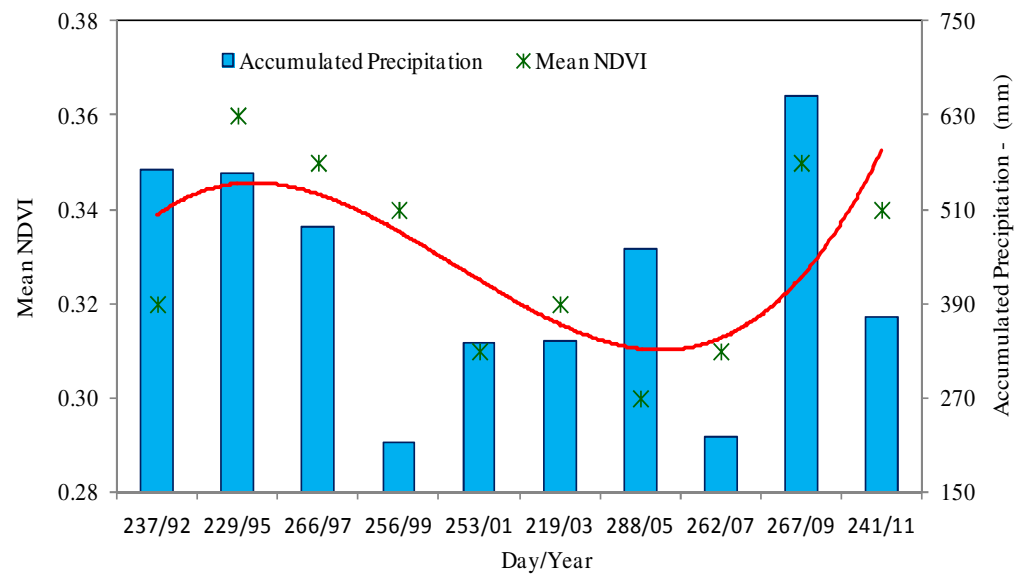

Figure 3. Averaged NDVI pixel values together with accumulated precipitation in the Nilo Coelho irrigation scheme, during the driest periods of the year from 1992 to 2001 for each DOY/Year from 1992 to 2011. DOY means Day of the Year.

Although during the years 1992, 1995 and 1997 there were less irrigated plots, the large amount of precipitation during the rainy periods kept the soil wet increasing the NDVI values for the "Caatinga" species inside the Nilo Coelho perimeter. On the other hand, the decline of rainfall amounts between the years of 1999 and 2007 reduce the NDVI 
values, recovering only in 2009 as the accumulated precipitation was high. Thus an increase in NDVI values with land use change cannot be detected as they are very dependent on the rainfall regime in the Brazilian Semiarid region.

The radiation balance among the different kind of vegetation is, to a large extent, affected by the surface albedo $\left(\alpha_{0}\right)$, which determines the short wave radiation that come back; and surface temperature $\left(\mathrm{T}_{0}\right)$, from which the emitted longwave radiation is directly proportional. The spatial variations of daily values of these parameters are shown in Figure 4.

(a) Surface albedo
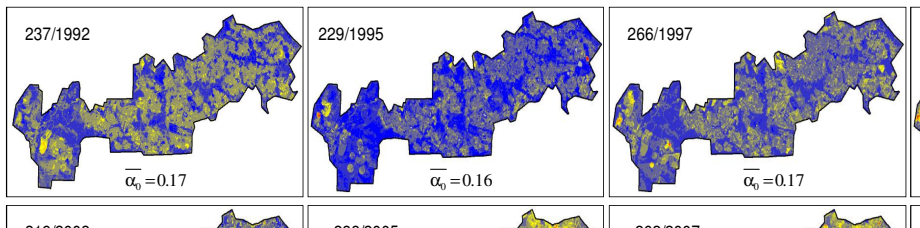
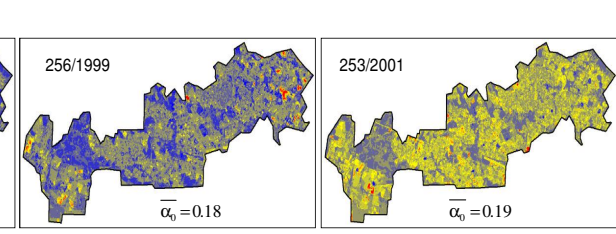

$\alpha_{0}$

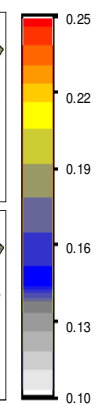

(b) Surface temperature
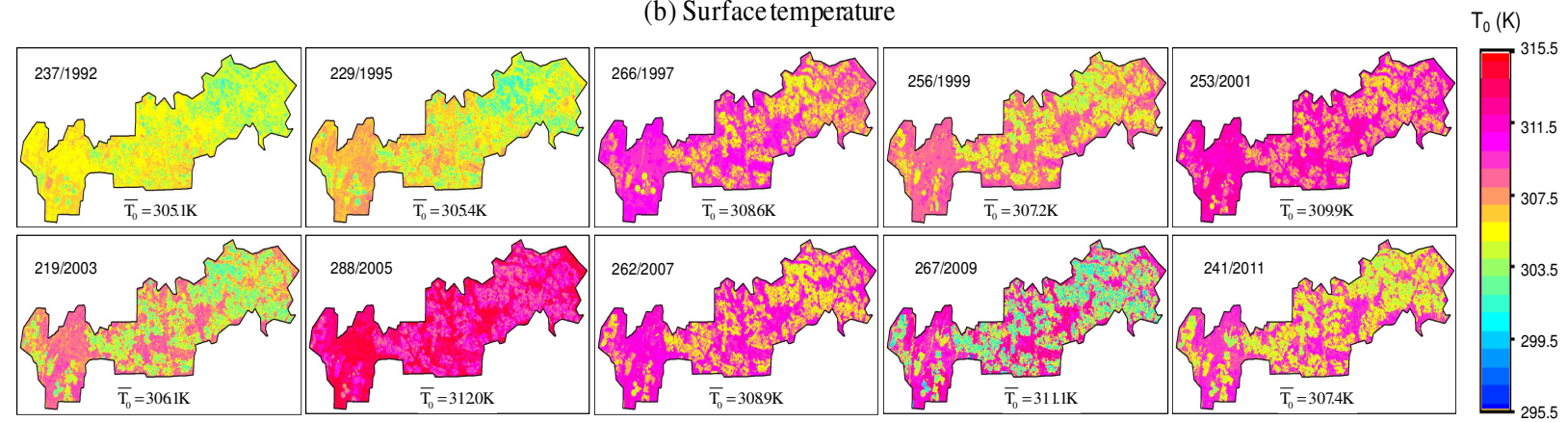

Figure 4. Spatial distributions of radiation balance relating parameters for the mixed agro-ecosystems at daily time scale in the Nilo Coelho irrigation scheme, Brazil, during the driest periods of the year from 1992 to 2001 for each DOY/Year. (a) surface albedo $\left(\alpha_{0}\right)$ and (b) surface temperature $\left(T_{0}\right)$. The bars mean average pixel values and DOY represents Day of the Year.

A dark land surface absorbs more solar radiation, and has a higher available energy than a bright surface. Yet, $\alpha_{0}$ also depends on moisture conditions ${ }^{12}$. Highest values occurred after 1997, as irrigated crops reflects more solar radiation than "Caatinga" , and after this year there was a quick replacement of the natural vegetation by agricultural plots. However, comparing with the spatial variation of NDVI values, $\alpha_{0}$ are more homogeneous with SD of 0.01 for all images (Figure 4a).

$\mathrm{T}_{0}$ affects the energy available interfering in the long wave radiation balance with lower values for irrigation conditions than those for dry areas, however it does not distinguish irrigated crops as well as NDVI does. One reason for this is the lower spatial resolution of the thermal band comparing with the visible ones. Even irrigation reducing $\mathrm{T}_{0}$ values, this is not the case when analysing the same period of the year in different dates. For example comparing the DOY/Year of 237/1992 and 241/2011, one can see the strong dependence on the thermal conditions, as shown by the mean RS $\downarrow$ values in Table 1 corresponding, respectively, to $\mathrm{T}_{\mathrm{a}}$ averages of 23.7 and $25.1^{\circ} \mathrm{C}$. Although the spatial variation of $\mathrm{T}_{0}$ is not so big, after 1997, when the crops started to be incremented, the SD values became higher than $1.7 \mathrm{~K}$. To see how $\alpha_{0}$ and $\mathrm{T}_{0}$ modified as a consequence of the land use change along the years the trends of their average pixel values were pictured in Figure 5. 

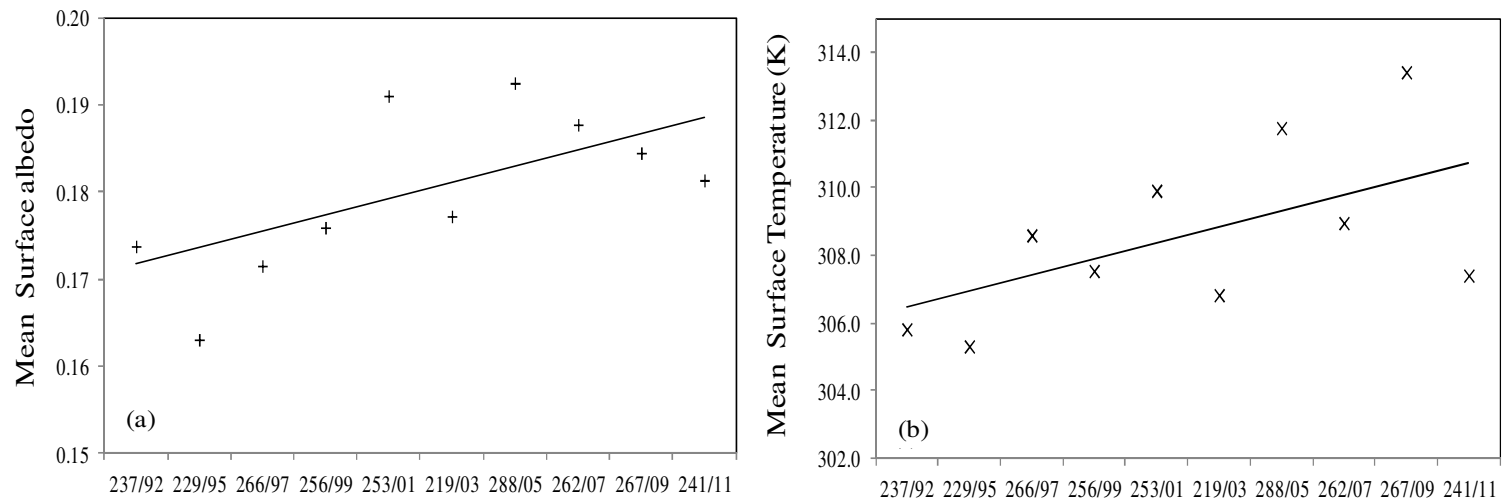

DOY/Year

Figure 5. Trends of the average pixel values of the radiation balance relating parameters along the years in the Nilo Coelho irrigation scheme, Brazil, during dry periods of from 1992 to 2001 for each DOY/Year. (a) surface albedo - $\alpha_{0}$ and (b) surface temperature - $\mathrm{T}_{0}$. DOY means Day of the Year.

For both radiation balance relating components, athought depending on the weather conditions according to the period of the year, there were incresing rates by factors of 0.003 for $\alpha_{0}$ and of $0.615 \mathrm{~K}$ for $\mathrm{T}_{0}$. The coupled effects should contribute to increases of the reflected and emmited radiation from the surface, affecting the available energy. By using interpolated data of RS $\downarrow$ and $\mathrm{T}_{\mathrm{a}}$ from the agrometeorological stations showed in Figure 1 together with $\alpha_{0}$ images at daily time scale, the slob equation was applied to retrieve the large scale $R_{n}$ values (Figure 6).

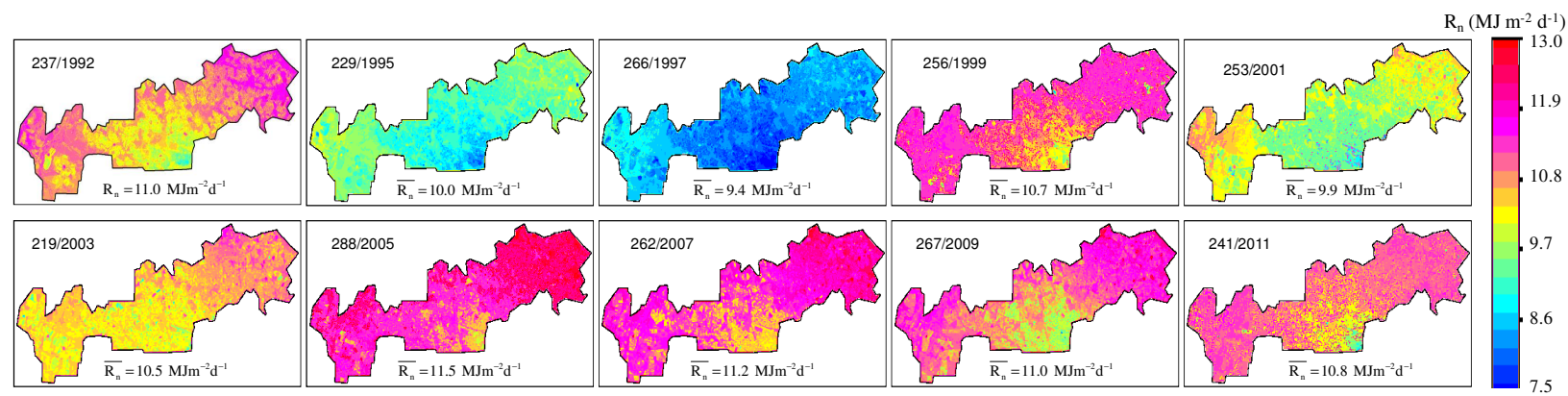

Figure 6. Spatial distributions of the net radiation $\left(\mathrm{R}_{\mathrm{n}}\right)$ for the mixed agro-ecosystems at daily time scale in the Nilo Coelho irrigation scheme, Brazil, during dry periods of the year from 1992 to 2001 for each DOY/Year. The bars mean average pixel values and DOY represents Day of the Year.

In general, there are no clear distinctions among the $R_{n}$ pixel values between irrigated and natural vegetation areas, as for example, comparing the similar periods represented by the images for 1992 and 2011, the largest difference in terms of land use change. Also, there are no large spatial differences with the SD values varying from 0.40 to $0.55 \mathrm{MJ} \mathrm{m}^{-2} \mathrm{~d}^{-1}$. The strong dependence of $R_{n}$ is on $R S \downarrow$, as one can see that the largest $R_{n}$ mean pixel value in 2005 (Figure 6) corresponds to the highest one of RS $\downarrow$ (Table 1).

As $R_{n}$ is most strongly dependent on RS $\downarrow$ than on moisture or vegetation conditions, being the largest effect of these last conditions on the partition of the available energy, the spatial variation of the $\lambda \mathrm{E}$ and $\mathrm{H}$ were analysed for the mixed agro-ecosystems in the irrigated perimeter (Figure 7). 


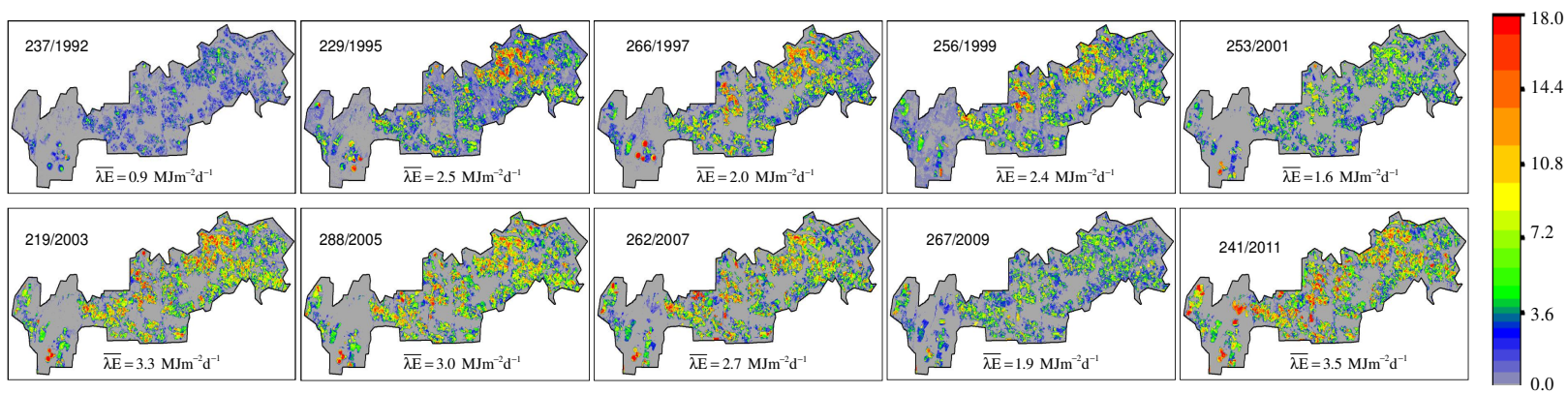

(b) Sensible heat flux

$\mathrm{H}\left(\mathrm{MJ} \mathrm{m}^{-2} \mathrm{~d}^{-1}\right)$

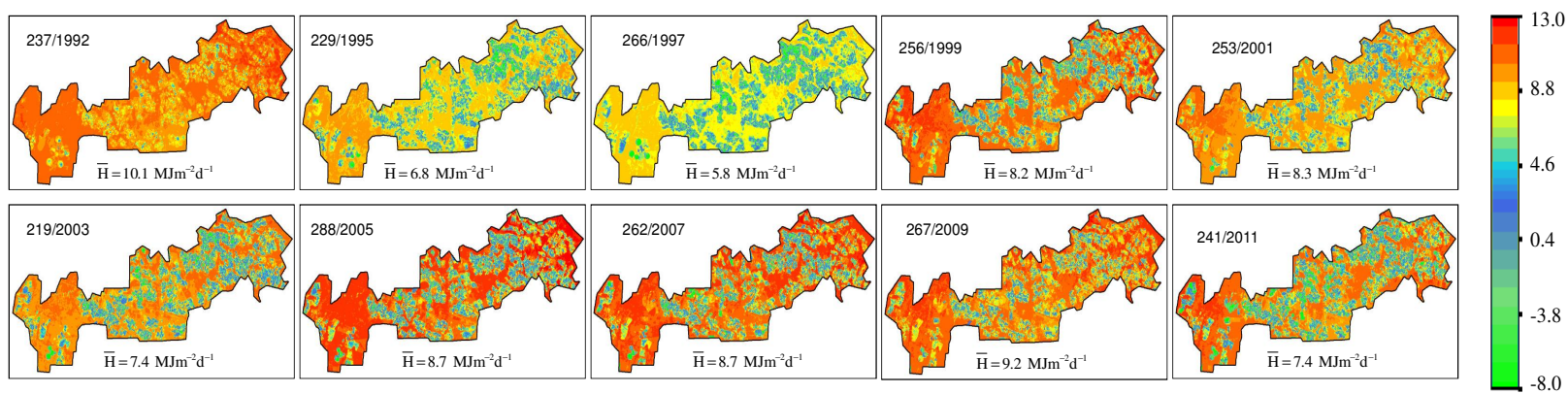

Figure 7. Spatial distributions of the energy fluxes for the mixed agro-ecosystems at daily time scale in the Nilo Coelho irrigation scheme, Brazil, during the driest periods of the year from 1992 to 2001 for each DOY/Year. (a) latent heat flux ( $\lambda \mathrm{E}$ ) and (b) sensible heat flux $(\mathrm{H})$. The bars mean average pixel values and DOY represents Day of the Year.

During this period, the $H / R_{n}$ fraction ranged from 0.92 to 0.69 , considering the entire perimeter area. From 1992 to 1997 , when the irrigated areas was starting to increase, high heat advection from the dry natural vegetation to irrigated areas is observed, making several $\lambda \mathrm{E} / \mathrm{R}_{\mathrm{n}}$ pixel values higher than one. The spatial variations of both fluxes are large, with an average SD of $3.5 \mathrm{MJ} \mathrm{m}^{-2} \mathrm{~d}^{-1}$. Only in 1992 one can see a small spatial flux variation with a SD value lower than $2.0 \mathrm{MJ} \mathrm{m}^{-2} \mathrm{~d}^{-1}$.

Clearly one can distinguish irrigated areas from "Caatinga" by the highest pixel values of $\lambda \mathrm{E}$ and the lowest ones of $\mathrm{H}$. This last energy flux is even negative in cropped areas, meaning heat horizontal advection from the warmer natural vegetation at the vicinities of irrigated plots. In relation to the daily $\lambda \mathrm{E}$ pixel values (Figure $7 \mathrm{a}$ ), their increments along the years are evident. Considering all Nilo Coelho perimeter, the average $\lambda \mathrm{E}$ values increased $390 \%$ with an average fraction of $\mathrm{R}_{\mathrm{n}}$ ranging from 8\% to 32\% from 1992 to 2011. This means that the introduction of irrigated crops increased almost four times the water vapour transferred to the lower atmosphere outside the rainy period. On the other hand, declines in $\mathrm{H}$ are also evident, with the average value in 1992 representing $210 \%$ of that for 2011.

The average energy flux pixel values in Figure 7 are low, when considering the whole perimeter, due to the heterogeneity caused by different types of vegetation. To have an idea of how the energy partition changed along the years in both, all area and irrigated areas, the trend of the average fractions of $\lambda E$ and $H$ to $R_{n}$ were analysed for both conditions applying a threshold value of $800 \mathrm{sm}^{-1}$ for $\mathrm{r}_{\mathrm{s}}$ and conditional functions with the use of the Equation 2 (Figure $8)$. 


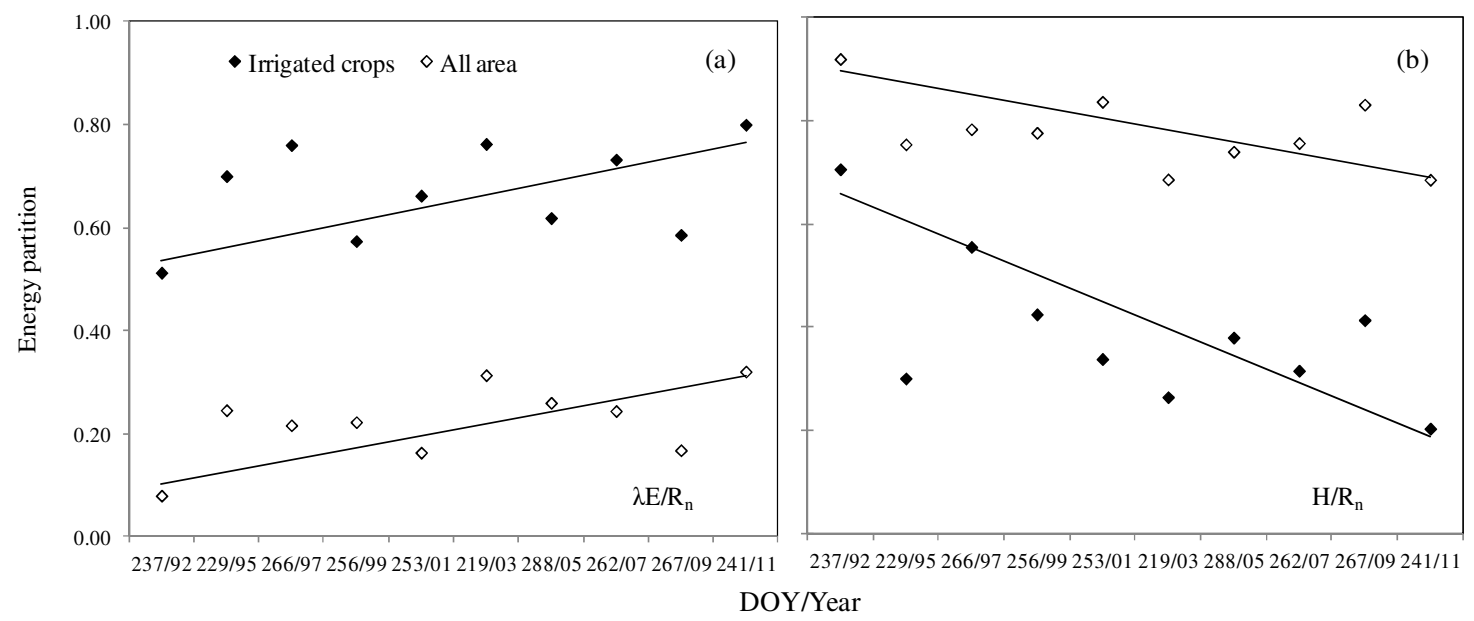

Figure 8. Average energy partition for the mixed agro-ecosystems at daily time scale in the Nilo Coelho irrigation scheme, Brazil, for both, the entire perimeter and only for irrigated plots, during the driest periods of the year from 1992 to 2001 for each DOY/Year. (a) fraction of net radiation used as latent heat flux $\left(\lambda E / R_{n}\right)$ and (b) as sensible heat flux $\left(H / R_{n}\right)$. DOY means Day of the Year.

Considering all area and irrigated conditions only, there are average increments of $2.3 \%$ and $2.5 \%$ in $\lambda \mathrm{E} / \mathrm{R}_{\mathrm{n}}$ values along the years, respectively (Figure 8a). Taking into account only irrigated areas the mean $\lambda \mathrm{E}$ increased from $5.6 \mathrm{MJ} \mathrm{m}^{-2} \mathrm{~d}^{-1}$ in 1992 to $8.4 \mathrm{MJ} \mathrm{m}^{-2} \mathrm{~d}^{-1}$ in 2011, equivalent to ET rates from 2.3 to $3.4 \mathrm{~mm} \mathrm{~d}^{-1}$ during this period. Analyzing the averaged $\mathrm{H}$ values along the years, under irrigation conditions an opposite situation is verified, ranging from $7.7 \mathrm{MJ} \mathrm{m}^{-2} \mathrm{~d}^{-1}$ to $2.2 \mathrm{MJ} \mathrm{m}^{-2} \mathrm{~d}^{-1}$, with decreases of 5.2 and $2.3 \%$ in $\mathrm{H} / \mathrm{R}_{\mathrm{n}}$ for irrigated and not irrigated areas, respectively.

Separating the areas not irrigated, the trend of the energy partition is more steady, with $\lambda E / R_{n}$ and $H / R_{n}$ around 0.06 and 0.93 , respectively, during the driest conditions of the year, with "Caatinga" converting large portions of the available energy into $\mathrm{H}$.

\section{CONCLUSIONS}

Coupling remote sensing parameters and agrometeorological data allowed the acquirement of the radiation and energy balance components on a large scale along the years, in a mixture of agro-ecosystems outside the rainy periods in the Nilo Coelho irrigation scheme, situated in the Brazilian semi-arid region. These investigations allowed a better understanding of the energy fluxes and the physical vegetation properties that affect these exchange processes, what are important for appraising the impact of land use changes on a large scale water balance. From the radiation balance viewer point, it could be concluded that net radiation values are much strongly dependent on global solar radiation independently of the type of vegetation. It was demonstrated that the daily radiation and energy balances can be estimated from instantaneous measurements of visible and thermal radiations, throughout modelling the ratio of the actual to reference evapotranspiration at the satellite overpass time and the daily net radiation once having daily weather data available. The averaged fractions of net radiation used as latent heat flux for the entire perimeter area increased from $8 \%$ to $32 \%$, while in irrigated areas these fractions ranged from 50 to $80 \%$, from 1992 to 2011 , revealing that in the measure that irrigated plots increase more the available energy is used in the evapotranspiration processes. On the other hand, there was a decrease in $\mathrm{H}$ from 71 to $20 \%$ of $\mathrm{R}_{\mathrm{n}}$ in irrigated areas, with the natural vegetation ("Caatinga") using around $90 \%$ of the available energy to heat the air during the driest periods of the year. The combination of satellite images and agrometorological stations, for modelling the radiation and energy balance components, proved to be useful for monitoring the climate and land use changes, when aiming the sustainability of the irrigated agriculture in the future, avoiding conflicts among different water users.

\section{ACKNOWLEDGEMENTS}

The research herein was supported by FACEPE (Science and Technology Foundation of Pernambuco state, Brazil), acknowledged for the financial support to the actual project on Water Productivity. 


\section{REFERENCES}

[1] Bastiaansssen, W. G. M., Brito, R. A. L., Bos, M. G., Souza, R. A., Cavalcanti, E. B., Bakker, M. M. "Low cost satellite data for monthly irrigation performance monitoring: Benchmarks from Nilo Coelho, Brazil," Irrig. Drain. Syst. 15, 53-79 (2001).

[2] Teixeira, A.H. de C.; Bastiaanssen, W.G.M.; Ahmad, M.D.; Bos, M.G. "Analysis of energy fluxes and vegetationatmosphere parameters in irrigated and natural ecosystems of semi-arid Brazil," J. Hydrol. 362, 110-127 (2008).

[3] Kimura, R., Bai, L., Fan, J., Takayama, N., Hinokidani, O. "Evapotranspiration estimation over the river basin of the Loess Plateau of China based on remote sensing," J. Arid Env. 68, 53-65 (2007).

[4] Akbari, M., Toomanian, N., Droogers, P., Bastiaanssen. W.G.M., Gieske, A. "Monitoring irrigation performance in Esfahan, Iran, using NOAA satellite imagery," Agric. Water Manage.88, 99-109 (2007).

[5] Bastiaansssen, W. G. M., Menenti, M., Feddes, R. A., Roerink, G. J. and Holtslag, A. A. M. "A remote sensing surface energy balance algorithm for land (SEBAL) 1. Formulation," J. Hydrol. 212-213, 198-212 (1998).

[6] Roerink, G. J., Su, Z. and Menenti, M. "S-SEBI: A simple remote sensing algorithm to estimate the surface energy balance," Phy. Chem. Earth, 25, 145- 157 (2000).

[7] Su, Z. "The Surface Energy Balance System (SEBS) for estimation of turbulent heat fluxes," Hydrol. Earth Syst. Sci. 6, 85-99 (2002).

[8] Teixeira, A. H. de C. "Determining regional actual evapotranspiration of irrigated and natural vegetation in the São Francisco river basin (Brazil) using remote sensing an Penman-Monteith equation,” Rem. Sens., 2: 1287-1319 (2010).

[9] Bruin de, H.A.R., Stricker, J.N.M. "Evaporation of grass under non-restricted soil moisture conditions," Hydrol.Sci. 45, 391-406 (2000).

[10] Teixeira, A. H. de C., Bastiaanssen, W.G.M, Ahmad, M-ud-D, Bos, M. G. "Reviewing SEBAL input parameters for assessing evapotranspiration and water productivity for the Low-Middle São Francisco River basin, Brazil Part A: Calibration and validation," Agric. For. Meteorol., 149, 477-490 (2009).

[11] Teixeira, A.H. de C. Water productivity assessments from field to large scale: a case study in the Brazilian semi-arid region; LAP Lambert Academic Publishing: Saarbrücken, Germany, 226p. (2009).

[12] Li, S.-G., Eugster, W., Asanuma, J, Kotani, A., Davaa, G., Oyunbaatar, D., Sugita, M. "Energy partitioning and its biophysical controls above a grazing steppe in central Mongólia," Agric. For. Meteorol. 137, 89-106 (2006). 